\title{
Acute Pancreatitis as a Long-term Complication of Pancreatectomy
}

\author{
Dong-Ya Huang', Qiang Li², Feng Guo', Kui-Rong Jiang', Cun-Cai Dai', Jun-Li Wu', Wen-Tao Gao', Yi Miao' \\ ${ }^{1}$ Department of Pancreas Center, The First Affiliated Hospital with Nanjing Medical University, Nanjing, Jiangsu 210029, China \\ 2Department of Surgical Intensive Care Unit, The First Affiliated Hospital with Nanjing Medical University, Nanjing, Jiangsu 210029, China
}

Dong-Ya Huang and Qiang Li contributed equally to this work.

To the Editor: Acute pancreatitis (AP) is a common digestive disorder with a broad spectrum of etiologies. ${ }^{[1]}$ Apart from gallstones and alcohol abuse which are two of most common etiologies of AP, all of other potential causes need to be considered. Pancreatectomy is the surgical removal of all or part of the pancreas, which includes pancreaticoduodenectomy (PD), distal pancreatectomy, segmental pancreatectomy, and total pancreatectomy. These procedures are used in the management of several diseases involving the pancreas, ampulla, extrahepatic bile duct, and duodenum. Based on the previous researches and studies, it was well accepted that pancreatectomy is associated with a series of common complications such as pancreatic fistula, postsurgical hemorrhage, and delayed gastric emptying. ${ }^{[2]}$ As a less frequent immediate surgical complication, postoperative AP occasionally appears just after the surgery on the pancreas. The mechanism involves direct trauma to the pancreatic parenchyma caused by pancreatectomy. To date, there has been little work on $\mathrm{AP}$ as a long-term complication following any pancreatectomy procedure.

This retrospective study was conducted over a time period from January 2013 to May 2015. Candidates of AP patients who were diagnosed with the disease after at least 1 month of pancreatectomy were recruited. According to the Revised Atlanta Classification, AP falls into the category of mild AP (MAP), moderately severe AP (MSAP), and severe AP (SAP). All of other etiological factors including alcohol abuse, gallstones, and medicine consumption were excluded before patients were suspected to have postpancreatectomy-induced pancreatitis.

A total of 742 patients who received pancreatectomy in the First Affiliated Hospital with Nanjing Medical University (Jiangsu, China) were recruited into the study. Among them, there were only eight patients who developed AP after at least one month of the surgery being included in the study, with $1.1 \%$ of the incidence rate of pancreatectomy-associated AP. All other causes, including alcohol, gallstones, hypertriglyceridemia, and other drugs, were excluded. In the eight patients, two received pylorus-preserving PD (PPPD), and the rest six distributed equally between standard $\mathrm{PD}$ and middle segment pancreatectomy. No AP was observed in the patients who

\begin{tabular}{|l|l|}
\hline \multicolumn{2}{|c|}{ Access this article online } \\
\hline Quick Response Code: & Website: \\
\hline & www.cmj.org \\
\cline { 2 - 2 } & \\
\hline
\end{tabular}

had distal pancreatectomy. It is equally prevalent in women and men. The age range of the eight patients was 24-64 years on the average of 46.7 years old. Six of the eight cases were classified as recurrent $\mathrm{AP}$, with averagely $2.4 \pm 1.8$ times of recurrence and $10.4 \pm 2.6$ days of length of hospital stay. The latency period from original resection to clinical presentation of AP was in the range of 144-935 days, with a median time of 385 days. Seventy-five percent of patients were diagnosed with MAP, and the remaining $25 \%$ of cases were identified with MSAP. No case of SAP was detected in the study.

Most of other patients were managed conservatively apart from two patients whose distal pancreatic ducts were observed with dilation through magnetic resonance cholangiopancreatography (MRCP). About the two patients, pancreaticojejunal anastomotic stenosis was observed, and the revision of the original anastomosis of pancreatic duct and jejunal mucosa was performed in the operation. There was no mortality and postoperative complication during the study, and all the cases obtained complete remission [Table 1].

Our study observed that only 8 patients were identified to come down with postoperative $\mathrm{AP}$ after at least 1 month of pancreatectomy in totally 742 cases of pancreatectomy, which revealed that AP was likely to be a rare long-term complication of pancreatectomy. Until now, the incidence and potential reasons of AP as a long-term complication of pancreatectomy remain unclear. A retrospective study reported that the incidence of pancreaticojejunostomy stricture (PJS) was nearly $2 \%$ in pancreaticoduodenectomy, and the patients presented with intractable pain at a mean of 12 months after pancreaticojejunostomy. ${ }^{[3]}$ The occurrence of a stricture is likely to induce obstructive pancreatitis in some individuals and may contribute to episodic pancreatitis events.

Address for correspondence: Dr. Yi Miao, Department of Pancreas Center, The First Affiliated Hospital of Nanjing Medical University, 300 Guangzhou Road, Nanjing, Jiangsu 210029, China

E-Mail: miaoyi@njmu.edu.cn

This is an open access journal, and articles are distributed under the terms of the Creative Commons Attribution-NonCommercial-ShareAlike 4.0 License, which allows others to remix, tweak, and build upon the work non-commercially, as long as appropriate credit is given and the new creations are licensed under the identical terms.

(C) 2018 Chinese Medical Journal i Produced by Wolters Kluwer - Medknow

Received: 14-03-2018 Edited by: Yi Cui

How to cite this article: Huang DY, Li Q, Guo F, Jiang KR, Dai CC,

Wu JL, Gao WT, Miao Y. Acute Pancreatitis as a Long-term Complication of Pancreatectomy. Chin Med J 2018;131:1755-6. 


\begin{tabular}{|c|c|c|c|c|c|c|c|c|}
\hline $\begin{array}{l}\text { Case } \\
\text { number }\end{array}$ & $\begin{array}{c}\text { Age } \\
\text { (years) }\end{array}$ & Gender & Primary disease & $\begin{array}{l}\text { Surgical } \\
\text { procedures }\end{array}$ & $\begin{array}{l}\text { First onset } \\
\text { time (months) }\end{array}$ & Recurrence & $\begin{array}{l}\text { LOS } \\
\text { (days) }\end{array}$ & Reoperation \\
\hline 1 & 24 & Female & $\begin{array}{l}\text { Intraductal papillary mucinous } \\
\text { neoplasm }\end{array}$ & PPPD & 15.5 & 4 & 8 & No \\
\hline 2 & 38 & Male & Pancreatic mucinous cystadenoma & MSP & 12.0 & 6 & 10 & No \\
\hline 3 & 64 & Male & Pancreatic mucinous cystadenoma & MSP & 13.7 & 2 & 9 & $\begin{array}{l}\text { Duct-to-mucosa } \\
\text { anastomosis }\end{array}$ \\
\hline 4 & 62 & Female & Periampullary inflammation & PPPD & 31.2 & 2 & 10 & No \\
\hline 5 & 63 & Female & $\begin{array}{l}\text { Gastric cancer with duodenum } \\
\text { invasion }\end{array}$ & PD & 4.8 & 1 & 12 & No \\
\hline 6 & 45 & Male & Mass-forming pancreatitis & $\mathrm{PD}$ & 8.0 & 2 & 8 & $\begin{array}{l}\text { Duct-to-mucosa } \\
\text { anastomosis }\end{array}$ \\
\hline 7 & 43 & Male & Pancreatic mucinous cystadenoma & $\mathrm{PD}$ & 18.0 & 1 & 16 & No \\
\hline 8 & 42 & Female & Pancreatic neuroendocrine tumor & MSP & 7.1 & 1 & 10 & No \\
\hline
\end{tabular}

PD: Pancreaticoduodenectomy; PPPD: Pylorus-preserving PD; MSP: Middle segment pancreatectomy; LOS: Length of hospital stay.

In the present study, positive finding was detected by the MRCP only in two individuals; however, even if the result of MRCP was normal, PJS cannot be ruled out directly. A previous study has found that secretin-MRCP could be a more useful approach to diagnose because it allows for a "functional" test of the remnant pancreas and is more discriminating for ductal stenosis than traditional static MRCP. ${ }^{[4]}$ Endoscopic retrograde cholangiopancreatography (ERCP) is one of the traditional endoscopic approaches for the treatment of symptomatic PJS, although it has met with limited technical success so far. Recently, multiple additional novel techniques involving direct transgastric puncture of the pancreatic duct under endoscopic ultrasonography guidance have been attained more technical and clinical success. ${ }^{[5]}$ Surgical reconstruction of PJS for intractable pain has been successful, whereas the operations are comparatively complicated and difficult. In the study, revision surgery for the original anastomosis of pancreatic duct and jejunal mucosa was carried out in only two patients whose distal pancreatic duct was detected to be dilated through MRCP. For the rest of patients, conservative treatment was performed. However, the true incidence of anastomotic stricture formation in this series may be underappreciated for lack of surgical evidence in the rest of six patients.

Based on the cases of the study, we suggested that patients who receive pancreatectomy are required to be warned about the possible complication of developing AP in the future time. Although the specific pathology of postoperative AP as a long-term complication is still not fully understood, stricture of the pancreaticojejunostomy is possibly one of the main causes of the rare complication. The relationship between PJS and AP can be observed by the means of secretin-MRCP. In most cases with PJS, we recommend minimally invasive methods, such as enteroscopy-assisted ERCP first; however, surgery will be considered if minimally invasive treatment is ineffective.

\section{Financial support and sponsorship}

This study was supported by a grant from the National Natural Science Foundation of China (No. 81672449).

\section{Conflicts of interest}

There are no conflicts of interest.

\section{RefEREnCes}

1. Johnson CD, Besselink MG, Carter R. Acute pancreatitis. BMJ 2014;349:g4859. doi: 10.1136/bmj.g4859.

2. Kapoor VK. Complications of pancreato-duodenectomy. Rozhl Chir 2016;95:53-9.

3. Demirjian AN, Kent TS, Callery MP, Vollmer CM. The inconsistent nature of symptomatic pancreatico-jejunostomy anastomotic strictures. HPB (Oxford) 2010;12:482-7. doi: 10.1111/j.1477-2574. 2010.00214.x

4. Testoni PA, Mariani A, Curioni S, Zanello A, Masci E. MRCP-secretin test-guided management of idiopathic recurrent pancreatitis: Long-term outcomes. Gastrointest Endosc 2008;67:1028-34. doi: 10.1016/j.gie.2007.09.007.

5. Mori N, Imazu H, Futagawa Y, Kanazawa K, Kakutani H, Sumiyama K, et al. EUS-guided rendezvous drainage for pancreatic duct obstruction from stenosis of pancreatojejunal anastomosis after pancreatoduodenostomy. Surg Laparosc Endosc Percutan Tech 2012;22:e236-8. doi: 10.1097/SLE.0b013e3182595aab. 